\title{
Applying Remote Sensing to Invasive Species Science- A Tamarisk Example
}

\section{The USGS Fort Collins Science Center's Invasive Species Science Branch}

Invasive, nonnative species of plants, animals, and disease organisms adversely affect the ecosystems that they enter. Like "biological wildfires," invasive species can quickly spread and have the potential to affect nearly all terrestrial and aquatic ecosystems. The threats caused by invasive species have become one of the greatest environmental challenges of the 21 st century in economic, environmental, and human health expenditures, with an estimated cost in the United States of more than $\$ 120$ billion per year (Pimentel and others, 2005). Managers within the U.S. Department of the Interior and of other public and private lands often rank invasive species as their top resource-management problem.

The Invasive Species Science Branch of the Fort Collins Science Center provides research and technical assistance relating to management concerns for invasive species, including understanding how these species are introduced, identifying areas vulnerable to invasion, forecasting invasions, and developing control methods.

Focusing in this fact sheet specifically on invasive weeds, some of the fundamental questions pertaining to their control are:

- Where is it now?

- What are the potential or realized ecological impacts of invasion?

- Where can it survive and thrive if introduced?

This fact sheet provides examples of how the U.S. Geological Survey (USGS),

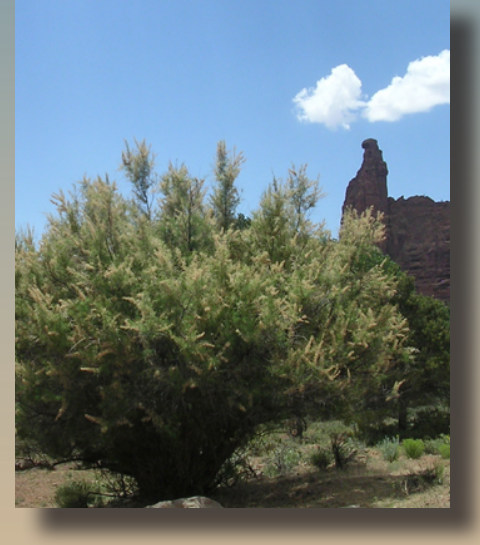

Tamarisk plant in bloom in Canyon de Chelly. Photo: Lindsay V. Reynolds. working with other federal agencies and university partners, are applying remote-sensing technologies to tamarisk (Tamarix spp), an invasive plant species, to address these key questions.

\section{Where is it Now? \\ Using Remote Sensing to Detect Tamarisk}

An important first step for containing plant infestations is to map their location. This is similar to other types of containment efforts, such as those performed on toxic chemical spills or wildfires. Mapping efforts provide baseline quantitative information with which management can estimate mitigation costs, define priorities, and develop removal and restoration strategies.

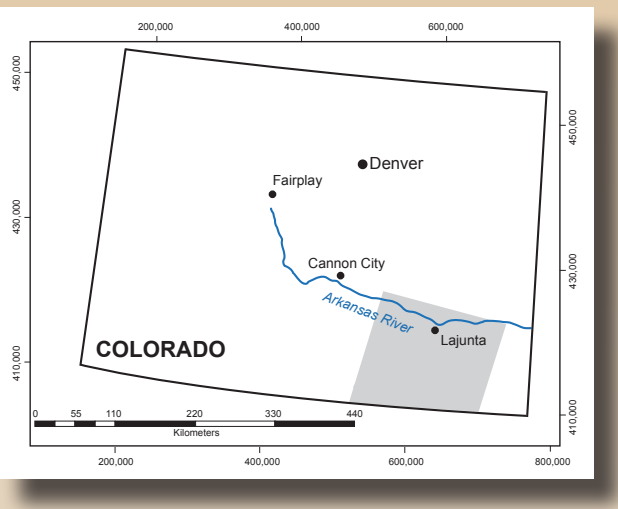

Study area for the work performed by Evangelista and others (2009).

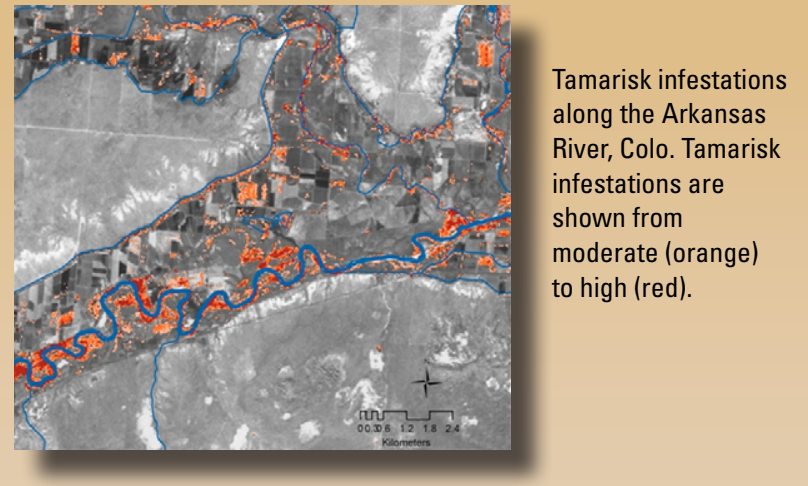

In a study applying machine-learning techniques with remote sensing, Evangelista and others (2009) demonstrated the ability to detect tamarisk invasions along the Arkansas River in Colorado with 90 percent accuracy within the Landsat imagery analyzed in their study. This work highlighted the importance of considering multiple Landsat scenes acquired over the course of a year. The study identified at least three different times during the growing season when phenological attributes of tamarisk can help distinguish the species from native vegetation and also indicated that these phenological differences are best detected using a time-series of Landsat imagery. 


\section{What are the Ecological Impacts?: Using Remote Sensing to Estimate Water Usage}

In many places along the lower Colorado River, it was assumed that tamarisk had replaced native shrubs and trees. Yet, based on either analysis or air photos taken over the Cibola National Wildlife Refuge (CNWR NWR), Ariz., Nagler and others (2009a) found that the fraction of land covered with vegetation in 2005-2007 was similar to amount of land occupied by native vegetation in 1938. This work exemplified the fact that plant leaf area and fractional cover are determinants of leaf-area transpiration and ground-area transpiration. The bar chart reproduced here as figure 5 shows how these four things vary over homogeneous tamarisk sites at Cibola NWR (Nagler and others, 2009b).

By combining field measurements with evapotranspiration (ET) estimates derived from MODIS, Nagler and others (2009a) found that although tamarisk grows better than native shrubs and trees in areas where salinity has increased, rates of transpiration are similar. This successfully demonstrates how remote sensing can be used to evaluate the ecological and hydrological effects of tamarisk invasion along the Colorado River. The finding that tamarisk does not have high rates of ET compared to native riparian species opens up the restoration alternative of combining tamarisk with native shrubs and trees in mixed stands to improve habitat value. This potential restoration option would be less daunting and seems more realistic than the option of completely removing and replacing all tamarisk with native species (Nagler and others, 2008; Nagler and others, 2009a).

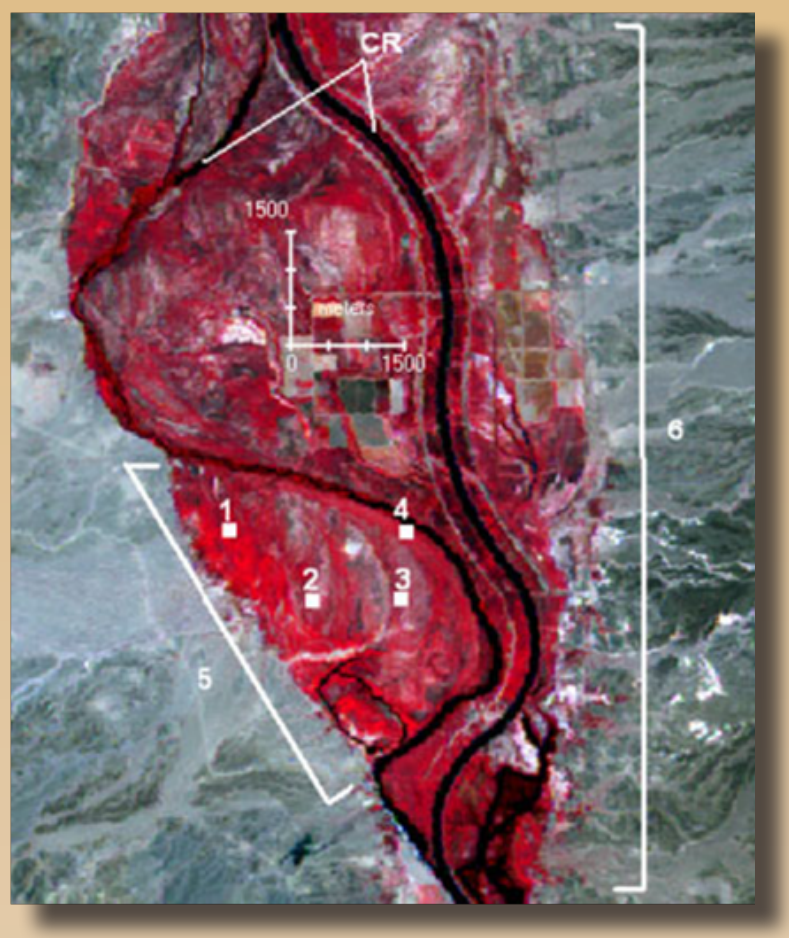

Tamarisk study sites at CNWR on the lower Colorado River, displayed on a 2005 Enhanced Thematic Mapper satellite image. CR points to the two channels of the Colorado River, with the old river channel on the left and the new channel on the right. Numbered study areas are: Slitherin (1), Diablo (2), Diablo East (3), Swamp (4), the lower portion of the CNWR (5), and the whole CNWR (6) (from Nagler and others, 2009a). (CNWR, Cibola National Wildlife Refuge; CR, Colorado River)
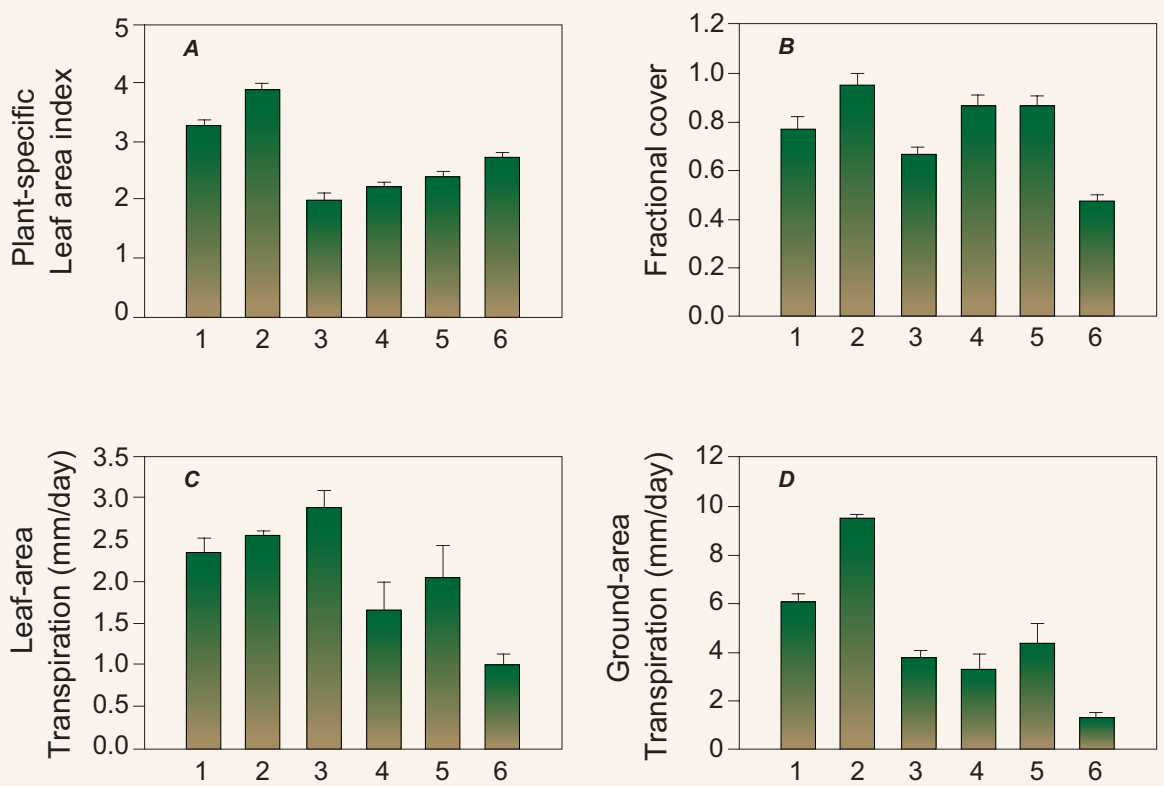

Graphs showing: A, tamarisk plant-specific leaf area index (LAPS); B, fractional cover; C, leaf-area transpiration; and D, ground-area transpiration at six sites at Cilobla National Wildlife Refuge on the Lower Colorado River: (1) Swamp, (2) Slitherin, (3) Diablo East, (4) Diablo Tower, (5) Diablo Southwest, and (6) Hot springs (from Nagler and others, 2009b). (mm/day, millimeters per day) 


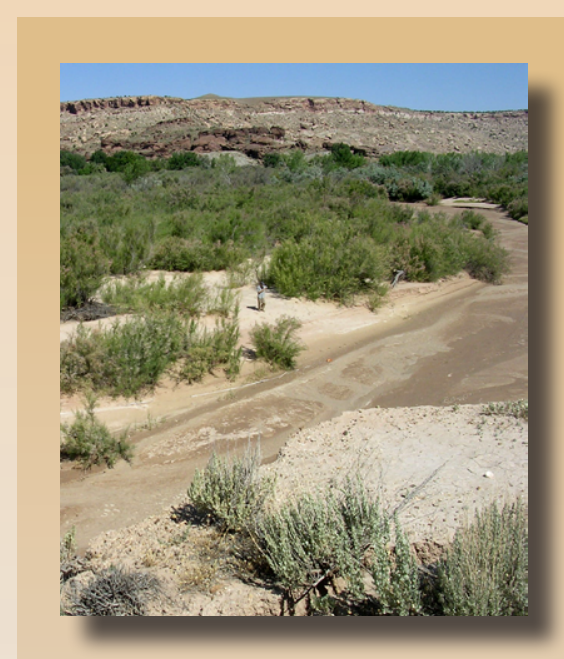

Tamarisk stand on Montezuma Wash in southeastern Utah. Photo: Lindsay V. Reynolds.

\section{Where can it Survive? Using Remote Sensing to Predict where Tamarisk will Grow and Thrive}

As the saying goes, "an ounce or prevention is worth a pound of cure." The same principle is true for invasive species. If land managers are informed of where a plant might invade, they can take precautionary steps to prevent its introduction or respond rapidly to any early introductions before the plant becomes established and costly or impossible to contain. Indeed, the U.S. National Invasive Species Council has made "early detection and rapid response" a key component to the national strategy to combat invasives (National Invasive Species Council, 2008). In an effort to map potential habitat for tamarisk, Morisette and others (2006) used a land-cover map and annual time series of vegetation health from Moderate Resolution Imaging Spectroradiometer (MODIS) to create national map showing areas susceptible to tamarisk invasion. The work integrated satellite data and tens of thousands of field-sampling points through logisticregression modeling to create a habitat-suitability map that had 90-percent accuracy. The study went on to demonstrate the use of the map by ranking the 48 continental states (and the District of Columbia) based on the rank of total area, as well as proportion of the state that was found to be "highly likely" and "moderately likely" habitat for tamarisk.

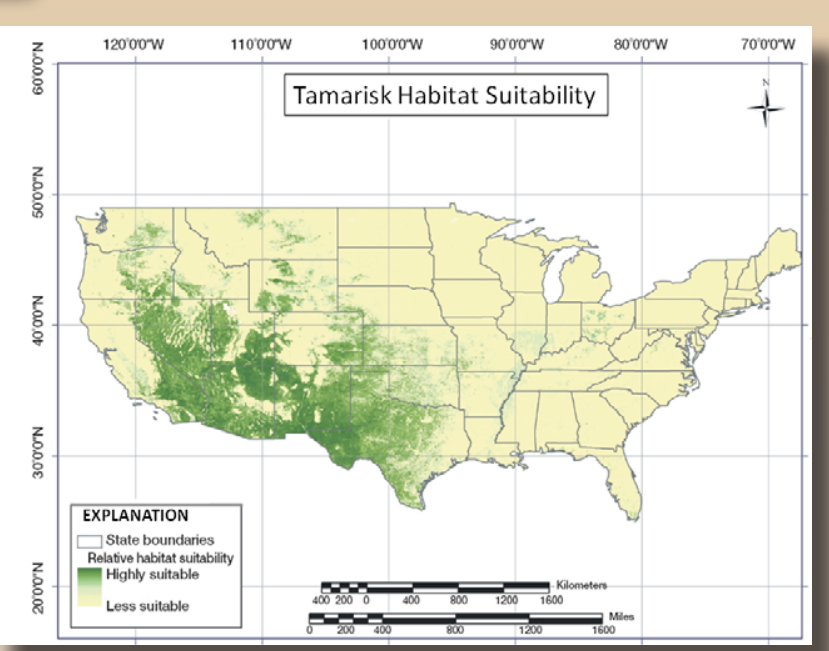

Tamarisk habitat-suitability map for the continental United States based on Moderate Resolution Imaging Spectroradiometer land use and vegetation data.

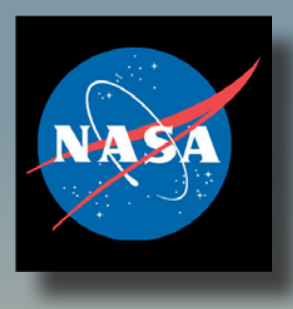

\section{Remote Sensing Data Sources}

The remote-sensing products highlighted here come from only two of the many satellitebased sensors collecting data from our Earth's surface. Existing work has used land future endeavors will explore) RADAR and LIDAR data, as well as hyperspectral and thermal sensors (National Academy of Sciences, 2007). The MODIS sensor is a key instrument aboard the National Aeronautics and Space Administration's (NASA) Terra (EOS AM) and Aqua (EOS PM) satellites. Terra MODIS and Aqua MODIS view the entire Earth's surface every 1 to 2 days, acquiring data in 36 spectral bands (groups of wavelengths). Since the Terra launch on December 18, 1999, the MODIS data have been improving our understanding of global dynamics and processes occurring on the land, in the oceans, and in the lower atmosphere.

The Landsat Program is a series of Earth-observing satellite missions jointly managed by NASA and the USGS. Since 1972, Landsat satellites have collected information about the Earth from space. This science, known as remote sensing, has matured with the Landsat Program. Landsat satellites have taken specialized digital photographs of Earth's continents and surrounding coastal regions for over three decades, enabling people to study many aspects of our planet and to evaluate the dynamic changes caused by both natural processes and human practices.

Further information at

MODIS: http://modis.gsfc.nasa.gov

Landsat http://landsat.usgs.gov/ and http://landsat.gsfc.nasa.gov/

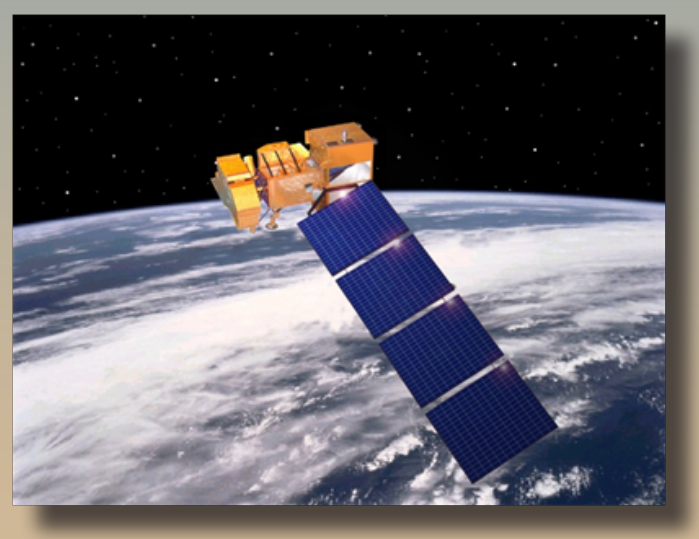




\section{The Future}

The results presented here reflect a small portion of work in this field. For example, a recent web-of-knowledge (2011) search on "remote sensing invasive species" revealed 106 papers. The work shown here and other existing research demonstrate that remote sensing can contribute to our knowledge of invasive species. In the spring of 2008, the USGS made the entire archive of Landsat scenes freely available to the public. In late 2012, the joint NASA and USGS "Landsat Data Continuity Mission" is scheduled to launch. With the existing archive being freely available and similar data continuing into the future, there is an opportunity to build on existing work. Future endeavors could consider additional species, new locations, retrospective analysis, and as well as strategies to implement operational monitoring techniques.

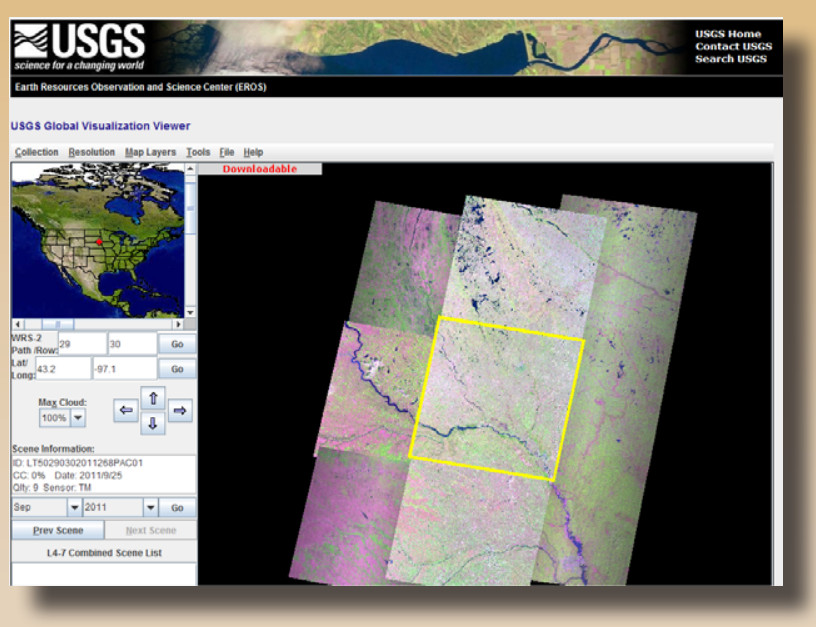

The Global Visualization Viewer where the entire archive of Landsat, and many other remote sensing data, are freely available (http://glovis.usgs.gov/).

\section{References:}

Evangelista, P.H., Stohlgren, T.J., Morisette, J.T., and Kumar, S., 2009, Mapping invasive Tamarisk (Tamarix)-A comparison of single-scene and timeseries analyses of remotely sensed data: Remote Sensing, v. 1, no. 3, p. 519-533; doi:10.3390/rs1030519.

Morisette, J.T., Jarnevich, C.S., Ullah, A., Cai, W., Pedelty, J.A., Gentle, J., Stohlgren, T.J., Schnase, J.L., 2006, A tamarisk habitat suitability map for the continental United States: Frontiers in Ecology and the Environment, v. 1, no. 4, p. 11-17.

Nagler, Pamela L., Glenn, Edward P., Didan, Kamel, Osterberg, John, Jordan, Finoa, and Cunningham, Jack, 2008, Wide-area estimates of stand structure and water use of Tamarix spp. on the Lower Colorado River-Implications for restoration and water management projects: Restoration Ecology, v. 16, no. 1, p. 136-145.

Nagler, P.L., Morino, K., Didan, K., Erker, J., Osterberg, J., Hultine, K.R., and Glenn, E.P., 2009a, Wide-area estimates of saltcedar (Tamarix spp.) evapotranspiration on the lower Colorado River measured by heat balance and remote sensing methods: Ecohydrology, v. 2, p. 18-33.

Nagler, Pamela L., Morino, Kiyomi, Murray, Scott, Osterberg, John, Glenn, and Edward P., 2009b, An empirical algorithm for estimating agricultural and riparian evapotranspiration using MODIS enhanced vegetation index and ground measurements of ETPart I-Description of method: Journal of Remote Sensing, Special Issue-Global Croplands, p. 12731297.
National Academy of Sciences, 2007, Earth science and applications from space-National imperatives for the next decade and beyond, Committee on Earth Science and Applications from Space-A community assessment and strategy for the future: Washington D.C., National Research Council, National Academies Press, accessed online August 22, 2011, at http://www.nap.edu/catalog.php?record_id=11820

National Invasive Species Council, 2008, 20082012 National invasive species management plan: Washington D.C., National Invasive Species Council, 35 p., accessed August 22, 2011 at http://www.invasivespecies.gov/main_nav/mn_NISC_ManagementPlan.html.

Pimentel, D., Zuniga, R., and Morrison, D., 2005, Update on the environmental and economic costs associated with alien invasive species in the United States: Ecological Economics, v. 52, p. 73-288.

Web of Knowledge, 2011, Web of Knowledge: New York, accessed August 22, 201, at http://wokinfo. $\mathrm{com} /$.
For more information, contact
Jeffrey T. Morisette, Ph.D
Assistant Center Director for Science
U.S. Geological Survey
Fort Collins Science Center
Invasive Species Science Branch
2150 Center Ave., Bldg C
Fort Collins, CO 80526-8118
Phone: 970-226-9144
Email: Jeffrey.t.morisette@usgs.gov 